\title{
THE PRACTICE OF PERFORMANCE-BASED CONTRACTING IN DEVELOPING COUNTRIES' PUBLIC PROCUREMENT: THE CASE OF ETHIOPIA
}

\author{
Baynesagn Asfaw Ambaw and Jan Telgen*
}

\begin{abstract}
Performance-Based Contracting (PBC) is widely accepted as a useful tool. It is believed that the use of PBC can assist the efficient utilization of the public resources. The objective of this research is to assess the extent of PBC application and the obstacles to applying it in the public procurement systems of developing countries. Interviews and factual analysis of procurement guidelines and contracts are used to collect data for this research. The analysis results indicate that the majority of public organizations have not yet used PBC even though it is allowed by the law. This is due partly to lack of clarity in the procurement laws and lack of capacity to use PBC.
\end{abstract}

\section{INTRODUCTION}

Since the last decade of years, public organizations have developed a long-term view of adding value to their procurement process and have adopted a new ways of contracting (Claassen, van Weele, \& van Raaij, 2008). Literature suggests that buyers, regardless of whether they are buying goods or services or works, need to add value or achieve an expected outcome with their procurement (Boykin, 2005; Eldridge \& Palmer, 2009; Heaviside \& Price, 2001). They have become aware that procurement has a strategic responsibility that can play a pivotal role in public

* Baynesagn Asfaw Ambaw is a Ph.D. candidate, Department of Technology Management and Supply, University of Twente, and an Instructor, Ethiopian Civil Service University. His research interest is in public procurement. Jan Telgen, Ph.D., is Professor, Department of Technology Management and Supply, University of Twente. His research interest is in applied operation research and public procurement.

Copyright $\odot 2017$ by PrAcademics Press 
expenditure management, improving of good governance, enhancing of economic development and commercial integration between and within countries. For achieving the above listed and other organizational objectives more efficiently and effectively, public organizations have started to use performance-based contracting (PBC) for their procurement process (Martin, 2007).

Applying a PBC system is believed to be a better option for achieving their expected objectives (Hypko, Tilebein, \& Gleich, 2010; Kim, Cohen, \& Netessine, 2007). However, very few of them do so, believing it to be a riskier contract with low levels of predictability of the contract results, while leaving more responsibility to the contractor (Hypko et al., 2010). However, in recent years, PBC has become a common practice in many government organizations (Becker, 2008; Hannah, Ray, Wandersman, \& Chien, 2010; Hypko et al., 2010). It is a description of how the finished products or services should perform over the agreed time period (Patil \& Molenaar, 2011). The approach describes what should be achieved in terms of results, but not exactly how the producers or service providers should achieve the results or fulfill the requirements of the clients (Anna, 2008). In other words, the procuring entity tells the supplier/contractor what they want done, not how the contractor has to do it (Sumo, van der Valk, \& van Weele, 2012). In this contracting approach, the contractor is only paid when he/she has been successful in achieving the pre-determined and mutually agreed objectives (Heinrich \& Choi, 2007). As a result, it minimizes the risk for the buyer of the money spent.

Using this contracting system, however, demands the procuring entities to have the required technical knowledge and skills with regard to how to spell out their requirements and manage the contract, and to be able to evaluate the end results (Brown \& Potoski, 2003). This helps them to become more successful in contract performance and adds value for both the client and contractor (Tineo, 2007). However, much of the public procurement in developing countries specifically is still contracted out based on input or process specifications (i.e. the traditional approach) and employs inefficient procurement practices (Becker, 2008; Kleemann \& Essig, 2013). In addition, many major public projects in developing countries face cost and schedule overruns and require a huge amount of extra budget to complete (Doer, Lewis, \& Eaton, 2005). For example, this is a 
common practice in Ethiopia in most public projects (Quinot \& Arrowsmith, 2013; World Bank \& Ethiopian Government, 2010).

Ethiopia is making a large investment in infrastructure as one of the key contributions to the country's development plan. About $62 \%$ of the annual budget is expended on procurement for infrastructure development in transport, energy, water, agriculture, education, health and other sectors (Quinot \& Arrowsmith, 2013). This comprises about 15\% of the GDP of the country. Transport alone constitutes $30 \%$ of the annual budget expenditure. For example, the Ethiopian Roads Authority signs a large number of contracts annually committing over ETB 29 billion. However, Ethiopian Public Procurement system has so far been characterized by the traditional procurement approach (World Bank \& Ethiopian Government, 2010), considering price as a main evaluation criterion. Using least cost approach as evaluation criteria avoids having to make judgments on qualitative aspects of bids, thus eliminating one opportunity to bias in the selection process. This, however, results in nothing but buying inferior quality products or works, project performance delays and cost overruns in Ethiopia (Quinot \& Arrowsmith, 2013). All of these procurement risks are mostly left to the public buyer once the goods are supplied. Of course, suppliers/contractors have paid for the activities but not for the results achieved (Patil \& Molenaar, 2011). These all encourages us to empirically prove the public procurement practice of Ethiopia. The results of this empirical study help the procuring entities to understand the concepts of PBC approach and make use it as a valuable contracting option. One of the reasons for this is that the traditional procurement system does not grant any motivation scheme for the contractors to innovate new ideas, to enhance efficiency, and to reduce the cost and time required for the contract (Shen, 2003). Rather, they intentionally delay the project performance time to enable them to request additional costs in the form of price escalation.

The rest of the paper is outlined as follows: after providing a literature review and analysis, the paper explains the methodologies employed for the research, and then presents the results and discussions of the data, respectively. Finally, it includes the conclusion and some remarks on the results. 


\section{LITERATURE REVIEW}

\section{The Meaning of PBC}

A specification is defined as a statement of the needs of the buyer. It is a description of needs - what the buyer wants to buy through which the buyer and the seller communicate. The specifications should be simple enough to be understood by the supplier or contractor and correctly and clearly express the needs of the buyers (Sabnis, 2005). More specifically, performance or functional specifications describe what results the supplier has to achieve for the procuring entity, whereas the technical specification describes the detail technical requirements and process of the contractor (Guo, Minchin, \& Ferragut, 2005).

The researchers underlined that using detailed technical specifications does not create a level playing field for the contractors to flexibly perform their contracts innovatively (Gruneberg, Hughes, \& Ancell, 2007). It does not allow them to include newly innovated concepts and ideas in the contract execution process so as to make the products and constructions fit for the contemporary technological demands of the public organizations (Lawther \& Martin, 2005). In addition, the system does not give any relief to the procuring entity from the procurement performance and functionality risks.

On the other hand, PBC is an approach to contracting that moves from the historical reliance on inputs and processes (telling the contractors how to perform the task) to the outputs, quality and outcome that enable them to measure the end results (Kleemann, Glas, \& Essig, 2012). The performance results, which are agreed to be measured based on outputs, qualities and outcomes, are tied with the contractor's compensation when the contractor achieves or exceeds its performance targets (Berkowitz, Gupta, Simpson, \& McWilliams, 2005). To balance the performance of the contractors, however, there should be a penalty commensurate with the compensation when the contractor's performance is below the performance targets (Kestenbaum \& Straight, 1995; Mannion \& Davies, 2008). The incentive schemes for the performance achieved can be offered in terms of lump sum money, contract extensions or recognition given for good performance (Shen, 2003). On the other hand, the contractor should be penalized if the performance is below the required level. 


\section{The Difference between PBC and Traditional Types of Contracting}

Transforming from the traditional contracting system to PBC entails the introduction of significant differences in the contracting process (Hypko et al., 2010). It involves changes in the basic role of the contracting parties in the contracting system, the assumptions on which the contract is based, the incentive schemes the contract is designed to award and the expectations from the contract (Hypko et al., 2010). The traditional contracting system specifies how the contractor should perform the contract (Boykin, 2005), whereas PBC defines only what results the contractor should achieve, leaving the contractor more flexibility to determine the best way to achieve the results expected by the buyer (Van Mossel \& Van der Valk, 2008). In contrary to the traditional approach, PBC is believed to encourage creativity and innovation by allowing contractors to decide on their own how to perform the task to achieve the expected results (Rosenthal, Fernandopulle, Ryu Song, \& Landon, 2004). Scholars agreed that when the contractors are free to choose how to perform the contract, but provided with clearly defined expected performance targets, they can design new ideas to fulfill the contract with reduced cost and time (Johnson \& Medcof, 2007; Lawther \& Martin, 2005).

The PBC system leads to the creation of long-term relationships and cooperation between the contracting parties (Johnson \& Medcof, 2007; Lawther \& Martin, 2005). Researchers agree that PBC is a longterm contracting system in which the contract relationship lasts through the performance period instead of ending after the goods are delivered or the service is rendered, as in a traditional contracting system (Claassen et al., 2008; Greiling, 2006; Kettner \& Martin, 1993). For example, for some contracts, the outcomes or impacts are not easily identified. A longer period of time is needed to measure the impacts of the contract (Claassen et al., 2008; Greiling, 2006; Kettner \& Martin, 1993). This longer contract duration influences the behaviors of the contracting parties in their relationship. It enhances their commitment to the success of the contract through cooperation and collaboration, whereas a traditional, regulatory contracting system focuses more on the applicability of rules and regulations in the contract performance process (Claassen et al., 2008). It is adversarial in nature, always refers to the contract provisions and focuses on fulfilling the requirements of the law rather than on the results. 
On the other hand, collaboration creates better communication between the contracting parties. It enhances togetherness, as both are working for one result, and it helps them work together to solve any problem that may arise during the contract performance period. Thus, under PBC, contracting parties can access and optimally utilize complementary resources as well as share information. As a result, it has a positive impact on the innovation of noble ideas and technologies. A summary of the difference in the two approaches are shown in Table 1.

TABLE 1

Basic Differences between the Two Contracting Approaches

\begin{tabular}{|l|l|}
\hline Descriptive Contracting & Performance-based Contracting \\
\hline $\begin{array}{l}\text { Pay for inputs, processes and } \\
\text { technologies }\end{array}$ & Pay for results \\
\hline Adversarial relationships & Cooperative relationships \\
\hline Regulations drive behavior & Payments for results drive behavior \\
\hline High certainty of results & Low certainty of results \\
\hline $\begin{array}{l}\text { Low responsibility to the } \\
\text { contractor }\end{array}$ & High responsibility to the contractor \\
\hline
\end{tabular}

\section{Characteristics of PBC}

We follow the literature stated here to explain the characteristics of PBC in the public procurement system. Buchanan \& Klinger (2007) noted that PBC explicitly consists of three major characteristics that make it different from the traditional contracting system: (i) There are clear and precisely defined objectives and performance indicators by which the contractors' performance can be measured, (ii) There should be performance indicators and data collection system to assess the results of the contractor and (iii) Performance leads to consequences for the contractor, such as provision of rewards or imposition of sanctions. Similarly, Tineo (2007) elaborated the PBC characteristics as three important elements that differentiate it from traditional input-based contracts. These are (i) designing performance specification, (ii) proving performance compliance and (iii) making payment only when the desired performance results are delivered. 
Generally, the list of literature was reviewed in relation to PBC. The literature review helped us to identify the most common characteristics of PBC. Based on that, we considered a contract to be performance-based if it has the following important characteristics:

1. It clearly defines the performance expectations (indicators) of the buyer (clearly understood baselines vs. expected results) without stating technical matters (Becker, 2008; Doer et al., 2005; Ng, Maull, \& Yip, 2009).

2. It establishes a proper data collection and evaluation system based on the indicators (Buchanan \& Klingner, 2007; Kleemann et al., 2012; Ng et al., 2009).

3. Performance leads to consequences for the contractor (payment, incentives or disincentives) (Becker, 2008; Kleemann et al., 2012; Rosenthal et al., 2004; Shen, 2003).

However, if the contract clearly defines performance expectation but misses either one or two of the other, it is considered that the PBC is partly applied and, importantly, that the concept has cascaded to the organization but has not been fully implemented. Furthermore, if all three criteria are not fulfilled in the contract, it is considered that the PBC concept is not known and not applied by that public organization. Essentially, the traditional system is used for their procurement activities.

Here, incentives and disincentives (penalties) in PBC mean that the contractors can be provided a reward for good performance, quality innovations and the risk of high investment by the contractor (Shen, 2003). The rewards can also be financial or non-financial. On the other hand, disincentives mean that in the PBC contracting approach, the contractors are penalized if they performed bellow the performance requirement.

Furthermore, there is also a contracting system that contains both technical and performance specifications simultaneously (Guo et al., 2005). It is used when the buyers clearly know their needs but want to be able to control the behaviors of the contractors in the contract performance process. However, the risk of the procurement is still left to the buyers (Gruneberg et al., 2007). In addition, like traditional contracting, it doesn't allow the contractors to flexibly perform their contracts and hence it restricts innovation. 
Similarly, the Federal Acquisition Regulation (FAR) of the United States of America subpart 37.6 is stated some important issues as the mandatory elements of PBC. Some of these elements are (i) the performance work statement (PWS), (ii) measurable performance standards, (iii) the assessment methods for contractor performance against performance standards and (iv) the use of positive and negative performance incentives when appropriate.

A number of studies have been conducted on PBC-related issues. The majority of the studies to date are not supported by strong empirical evidence, but instead focus more on the theoretical aspects of PBC (Hannah et al., 2010; Lam, Chan, \& Chan, 2007; Ng \& Nudurupati, 2010; Shen, 2003; Straub \& van Mossel, 2007; Tineo, 2007). In addition, the extent to which PBC is practiced in the context of developing countries has not been assessed in a systematic manner through independent research. If practiced, its effectiveness as compared to the traditional approach has not been evaluated. If not practiced, the reasons for non-practice or partial practice have not been well investigated. Thus, the objective of this research is to contribute to filling this research gap in the context of developing countries by taking up the case of Ethiopia.

To achieve such research objectives, the researchers sought to answer the following research questions:

i. To what extent are public organizations in Ethiopia practicing PBC in their procurement system?

ii. If PBC is not practiced at all or is partially practiced, what are the underlying reasons behind such level of practice?

iii. If PBC is fully or partially practiced, does it work better than the traditional prescriptive approach in specific acquisition areas?

\section{THE METHODOLOGY EMPLOYED}

Exploratory research was used to conduct this study. It enables the researchers to better understand the existing situation (Twinn, 1997). It is not a means to arrive at final conclusions; rather, it helps to produce a hypothesis about what is actually going on and to lay a foundation for further study (Elo \& Kyngas, 2008). Thus, sampling for this study was not aimed at to show the representativeness but at inductively exploring the practice of PBC in the public sector and 
generating new insights through in-depth investigation. For such type of studies a small number of cases are recommended to analyze (Kolar, Ahmad, Chan, \& Erickson, 2015).

To do this research work, a two-phase approach was chosen for the research design. In the first phase, a factual analysis of the procurement guidelines and the contracts used by Ethiopian public agencies was carried out to determine the extent to which PBC is allowed, regulated and practiced in the sample organizations. In the second phase, personal interviews were conducted with key informants to find out the underlying reasons that caused the existing level of practice of PBC in the public organizations.

\section{Procurement Laws}

Regarding the first phase, the procurement guidelines of the Ethiopian government, the World Bank and the African Development Bank were critically assessed to check whether they allow using PBC in the procurement of goods, works and services in the public procurement system of Ethiopia. The reason behind the need to assess different procurement guidelines (especially the guidelines of World Bank and African Development bank) is that, in most developing countries including Ethiopia, the government projects are partly or fully financed either by donors and international development agencies such as the World Bank, or by the government. As a result, sometimes the government is forced to use the procurement guidelines of the donors as well.

\section{Procurement Contracts}

To assess whether the public organizations used PBC in their procurement system, a comprehensive list of procurement contracts was formally requested via an official written letter presented to 15 public bodies in the federal government of Ethiopia. The researchers purposively selected 15 public organizations of a large-budget group from the federal government, of which 13 public organizations allowed us to view their procurement contracts. The other two public bodies did not offer their cooperation in accessing their procurement contracts. The public organizations in the large-budget group are those organizations for which the government allocates the larger share of the country's annual budget for different developmental activities. These organizations were consciously selected in order to 
gain an insight into their PBC practice. This focus on such largebudget organizations enables us to find varieties of contracts for different types of procurement (contracts for procurement of goods, works and services).

After getting permission from the head of each public body, we used the contract register as a base to choose the list of contracts from each type of procurement. The lists were classified into four categories: goods, works, consultancy services and non-consultancy services. The consultancy contracts were grouped by selection method, namely: Quality and Cost-based Selection (QCBS), Least Cost Selection (LCS), Fixed Budget Selection (FBS) and Consultant's Qualification Selection (CQS), while the goods and works contracts were classified by procurement method: International Competitive Bid (ICB), National Competitive Bid (NCB), Restricted Tender (RT) and Request for Quotation (RFQ). To enable a complete analysis of procurement transactions, the researchers collected delivered contracts. Thus, we found 312 contracts for our analysis from the contract register from those 13 public organizations. This equates on average to 12 contracts per year for procurement of goods, works and services for each public organization. From these 13 organizations, 131 contracts of different projects from budget years 2012/13 and 2013/14 were collected from a total of 312 contracts.

Some organizations have better filing systems than others. Due to the lack of proper filing systems, finding the files of selected contracts was very difficult for the researchers. The researchers tried to include contracts from each type of procurement (from goods, works and services) in each of the organizations selected for this study. But some of the contracts selected from the contract register either were not filed or were missing some important sections. This is mainly because of the high turnover of the procurement staff; in some cases, the existing staff did not even know where the contracts were filed. Because of this, we ended up finding more contracts from some organizations than from others.

We exhaustively searched and included 131 contracts for analysis. Considering the challenges of getting contracts from the files when the time period was longer, we decided to focus on analyzing the procurement practices of the 2012/2013 and 2013/2014 fiscal years. These 131 contracts were considered 
sufficient to determine the extent of the practice of PBC in Ethiopian public organizations.

\section{Interviews}

To enhance the validity of the information from the procurement rules and contracts analysis, face to face interviews were organized for three different groups of respondents: 16 officials from the Federal Public Procurement and Property Administration Agency (PPPAA) and other procuring entities whose contracts are not included in the analysis; 14 procurement officials from public organizations who are not implementing PBC but whose contracts are included in the analysis; and 7 officials from those organizations implementing PBC, totaling 37 participants. Since all of the interviewees were graduates, they could express their ideas in English without any problem, and we used the English language to conduct the interviews. The researchers explained to the interviewees how the information provided by them would be treated confidentially. The interviews helped us to understand a broader picture of their practice of PBC, the challenges to applying PBC and the future plans they have in relation to PBC applicability. The interviews were tape recorded and transcribed by the researchers. The interviews lasted between 25 to 30 minutes and were conducted at the respondents' offices. A summary of the interview respondents is provided in Figure 1.

To ensure the validity and reliability of the data, the researchers made clear the objectives of the research and created relationships of trust with the informants. After collecting the data, we got to know our data. The data screening process was started first by listening to

FIGURE 1

Summary of the Interview Respondents

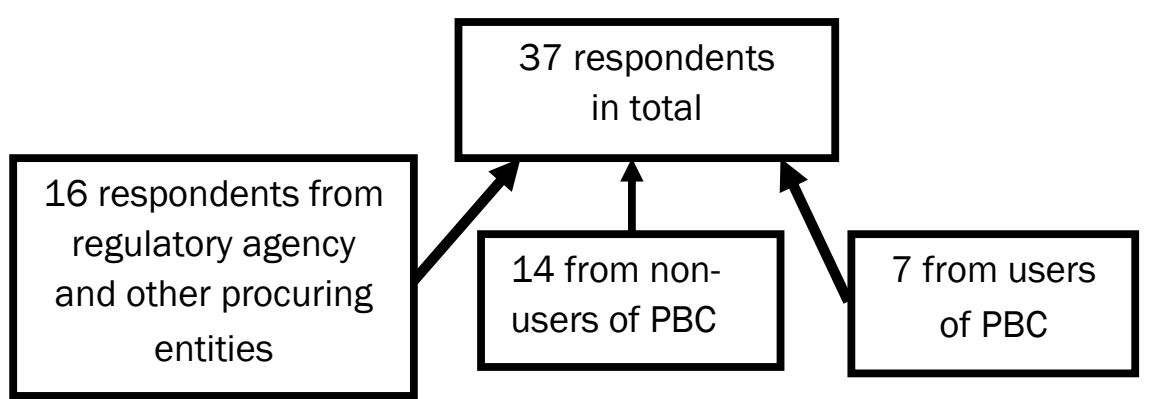


the records, transcribing the records and then reading over the written transcripts. After finalizing the transcription process, we sent the transcribed data to the informants for confirmation. The researchers again reread the transcripts one by one very carefully and studied the notes to list key ideas and recurrent themes of the interview. Then the relevant pieces, such as words, phrases and sentences were ranked. These ranks are the concepts and opinions of the interviewee. This ranking process is called coding.

The decision for coding was based on some important reasons, such as things explicitly stated as important by the interviewee, words or phrases repeated by the different interviewees and similarity to theories and previously published papers. Our aim here was to conceptualize the pattern of the data collection process without any bias.

The next step was choosing the most important codes and creating categories by bringing different codes together. Here, some of the initial codes were dropped, and by combining some others new codes were created. Then the researchers categorized the codes based on the order of frequency. The researchers were very careful in managing all these processes to enhance the reliability of the data in our research work. Finally, we started the write-ups and analysis based on previous studies published in relevant scientific journals.

\section{RESULTS}

\section{Analysis of the Procurement Laws}

The procurement laws of the Ethiopian government, the World Bank and African Development Bank were separately analyzed as follows.

\section{Ethiopian Public Procurement laws}

The Federal Democratic Republic Government of Ethiopia passed public procurement rules that contain the concept of PBC (The Federal Government of Ethiopia, 2009). Article 29 of the Public Procurement and Property Administration Proclamation number $649 / 2009$ clearly states that the specifications to be used by public bodies, as far as possible, have to be expressed in terms of performance, instead of describing the characteristics. Otherwise, they have to be expressed based on the national standards, where 
such exists, or the internationally recognized standards or building codes.' This typically allows the procuring entities to use PBC in their procurement activities. The law, however, does not prohibit using the detailed technical specifications for their procurement.

For the convenience of application of the proclamation, the Ministry of Finance and Economic Development (MoFED) issued a directive in June 2010. But the directive neither contains elements of PBC nor prohibits them from using PBC. Furthermore, it does not show how PBC could be applied or for what type of contract it could be used. This results in difficulty for the public organizations in clearly understanding and using PBC for their procurement process. In addition, the regulatory authority can also face difficulties in enforcing the procuring entities' use of PBC in their procurement process. The absence of clear guidelines on how to use PBC has resulted in a lack of a uniform understanding of the application procedures, and different organizations apply PBC differently based on their level of understanding.

\section{World Bank Procurement Laws}

In the World Bank (WB) Procurement Guidelines dated January 2011, Article 2.19 for procurement of goods, works and nonconsultancy services states that 'the standards and the technical specifications stated in the bidding document shall promote the broadest competition possible, while assuring the critical performance or other requirements for the goods and/or works under procurement.' In addition, the guideline states that the borrowers are expected to use internationally accepted standards to specify their needs with which the equipment, materials or workmanship shall comply, but the borrowers also allowed to use the national standards where such international standards are unavailable or inappropriate. However, in all cases, the bidding documents are expected to state the equipment, material or workmanship meeting other standards, which promise at least substantial equivalence to the international ones.

The Bank guidelines neither state the use of performance specifications in the procurement process, nor provide any reference materials for how to use PBC in Bank-financed projects. Even though the Bank procurement guidelines do not clearly specify whether the procuring entities are to use PBC or not for procurement of Bank- 
financed projects, they encourage the borrowers to ensure the achievement of critical performance or other standards for the goods and/or works under procurement. But it is not clear what critical performance means for the borrowers. Nevertheless, the guidelines do not have articles in them that can prohibit using PBC in Bankfinanced procurement procedures.

\section{African Development Bank Procurement Laws}

The procurement guidelines of the African Development Bank (AfDB) allow using PBC for projects financed partly or fully by the AfDB. According to the Procurement and Fiduciary Services Department, Articles 3.14 \& 3.15 of Procurement and Fiduciary Services Department (2008) define performance-based contracting and clearly explain how and for which type of procurement PBC can be used for Bank-financed projects. This guideline allows the borrower to use PBC for "the provision of services to be paid based on results achieved and the design, supply, construction (or rehabilitation) and commissioning' of the facility or service to be operated by the borrower. According to the AfDB procurement guidelines, PBC can also be used for the "design, supply and construction of facilities and provision of services for its operation and maintenance for the defined period of time after commissioning.' For such types of contracts, the borrowers are allowed to use PBC for projects that are fully or partly financed by the AfDB. In addition, the guideline clarifies how the payment is to be made based on the quantity of outputs delivered to a level of quality satisfying the functional and performance needs of the buyer. The contents of the three procurement laws are summarized in Table 2.

TABLE 2

The Contents of the Procurement Laws in Relation to PBC

\begin{tabular}{|l|c|c|c|}
\hline Requirement & Ethiopian law & WB laws & AfDB laws \\
\hline Must use PBC & No & No & Yes \\
\hline Encouraged to use PBC & Yes & Yes & Yes \\
\hline Allowed to use PBC & Yes & Yes & Yes \\
\hline Prohibited to use PBC & No & No & No \\
\hline
\end{tabular}

Source: Developed by the authors. 


\section{Results of the Contract Analysis}

The contracts included in the samples were 131 of the total estimated 312 contracts from 13 public organizations in budget years 2012/13 and 2013/2014. The 131 contracts analyzed account for about $42 \%$ of the total contracts from 13 public organizations. This enables us to develop a picture of the extent of PBC application in the public sector. Table 3 summarizes the total number of contracts included in the sample and the composition of the contracts with respect to the procurement type.

TABLE 3

Composition of Contracts with Respect to Type of Procurement

\begin{tabular}{|c|c|c|}
\hline Procurement types & No. of contracts & Percent (\%) \\
\hline Goods & 77 & 58.83 \\
\hline Works & 27 & 20.6 \\
\hline Consultancy services & 16 & 12.2 \\
\hline Non-consultancy services & 11 & 8.4 \\
\hline Total & 131 & 100.0 \\
\hline
\end{tabular}

Source: Computed by the authors.

Regarding the procurement methods used, of the contracts analyzed, 53 contracts (40.5\%) used the ICB method; 74 contracts (56.5\%) used the NCB method; three contracts (2.3\%) used the RT method and the remaining one contract $(0.8 \%)$ used the shopping method. More specifically to the consultants selection methods, 10 of the contracts (62.5\%) are used QCBS, 3 contracts $(18.75 \%)$ used LCS, and the other 1 contract (6.25\%) used CQS.

Each contract was analyzed based on the three criteria developed from the literature. The results in Table 4 showed that from the total of 131 contracts, PBC was fully applied only in seven (5.4\%) of the sample contracts. These contracts fulfilled all the PBC criteria. The other 43 (32.8\%) contracts contain some concepts of PBC but missed either one or two of the criteria of PBC or functional specifications. Rather, contain more of the detailed technical specification together with some concepts of performance specification. These 
TABLE 4

Practice of PBC System

\begin{tabular}{|l|c|c|}
\hline Practice & $\begin{array}{c}\text { No. of } \\
\text { contracts }\end{array}$ & $\begin{array}{c}\text { Percent } \\
(\%)\end{array}$ \\
\hline PBC not practiced at all & 81 & 61.8 \\
\hline $\begin{array}{l}\text { PBC partially practiced } \\
\text { Payment is not related to performance }=32 \\
\text { Only penalties included, not incentives }=43 \\
\text { Lack of measurable evaluation criteria }=11\end{array}$ & 43 & 32.8 \\
\hline PBC fully practiced & & \\
\hline \multicolumn{1}{|c|}{ Total } & 131 & 100 \\
\hline
\end{tabular}

organizations knew the concept of PBC but did not practice it fully. In the remaining $81(61.8 \%)$ contracts, the traditional, descriptive system of contracting was used.

Of 13 federal public procuring entities, only one organization started to fully apply PBC in some selected contracts, and the other six procuring entities used it partly by including some concepts of PBC together with detailed technical specifications. The other procuring entities neither used the PBC system of contracting at all nor included any concepts of PBC/functionality together with their detailed technical specifications. All the contracts that used PBC were designbuild-transfer types of contracts for road construction projects. The other 43 contracts that contain technical and performance/functional specifications were mostly used for works contracts in six public organizations. In addition to the performance results achieved, incentives can also be provided for quality innovations and the risk of high investment by the contractor (see details in Table 5).

\section{Results of Interview Analysis}

The first extensive interview was conducted with 16 respondents, including PPPAA officials and officials from other 11 procuring entities, mainly procurement department heads and procurement managers. In order to capture an in-depth understanding of the extent of the application of PBC in the public procurement system and the reasons for not practicing PBC more in their procurement system, we used open-ended questions. Since the interview 
questions were open-ended, the PBC issues were discussed more broadly, and hence the researchers were able to develop a broader idea of the impediments to the practice of PBC in the public sector (the interview questions are available from the authors). The interview was recorded and subsequently transcribed. One of the interview questions was "Why is PBC not practiced more in the public

TABLE 5

Number of Contracts Collected Across the Procuring Entities

\begin{tabular}{|c|c|c|c|c|c|}
\hline \multirow[b]{2}{*}{ No. } & \multirow[b]{2}{*}{ Procuring entity } & \multirow[b]{2}{*}{ 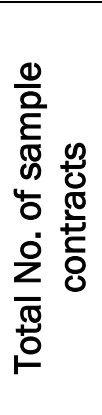 } & \multicolumn{3}{|c|}{$\begin{array}{l}\text { Number of } \\
\text { Contracts }\end{array}$} \\
\hline & & & 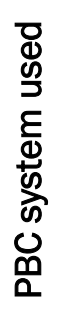 & 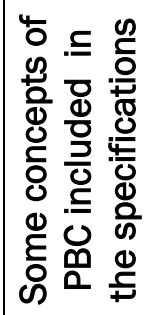 & 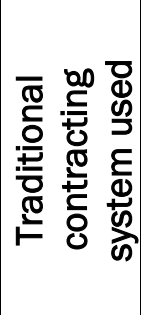 \\
\hline 1 & Addis Ababa University & 3 & 0 & 0 & 3 \\
\hline 2 & Ethiopian Roads Authority & 17 & 7 & 4 & 6 \\
\hline 3 & Ethiopian Civil Service University & 12 & 0 & 0 & 12 \\
\hline 4 & $\begin{array}{l}\text { Ethiopian Revenue and Customs } \\
\text { Authority }\end{array}$ & 16 & 0 & 0 & 16 \\
\hline 5 & Ministry of Agriculture & 5 & 0 & 3 & 2 \\
\hline 6 & Ministry of Education & 10 & 0 & 0 & 10 \\
\hline 7 & $\begin{array}{l}\text { Ministry of Finance and } \\
\text { Economic Development }\end{array}$ & 3 & 0 & 0 & 3 \\
\hline 8 & Ministry of Health & 11 & 0 & 6 & 5 \\
\hline 9 & $\begin{array}{l}\text { Ministry of Urban Development, } \\
\text { Housing and Construction }\end{array}$ & 17 & 0 & 13 & 4 \\
\hline 10 & Ministry of Water and Energy & 9 & 0 & 5 & 4 \\
\hline 11 & $\begin{array}{l}\text { Public Procurement and Disposal } \\
\text { Agency }\end{array}$ & 7 & 0 & 0 & 7 \\
\hline 12 & Ministry of Transport & 2 & 0 & 0 & 2 \\
\hline 13 & Sugar Corporation & 18 & 0 & 12 & 8 \\
\hline & Total & 131 & 7 & 43 & 81 \\
\hline
\end{tabular}


procurement system of Ethiopia, even though it is allowed in the public procurement law?'

While the respondents listed a number of points, a summary of the main reasons is shown in Table 6. Of the reasons for the low practice of PBC in the public sector, the lack of a clear legal framework, the lack of institutionalized training programs and the high turnover of procurement professionals are the main ones that were discussed by $94 \%, 88 \%$ and $63 \%$ of the respondents, respectively. Furthermore, a few respondents also raised issues like transparency problems and fear of corruption in using PBC.

TABLE 6

Reasons for Low Practice of PBC

\begin{tabular}{|l|r|r|}
\hline \multirow{2}{*}{ List of Reasons } & \multicolumn{2}{|l|}{ Respondents } \\
\cline { 2 - 4 } & \multicolumn{1}{|l|}{$\begin{array}{l}\text { \# } \\
\text { Lack of clear legal framework }\end{array}$} & 15 \\
\hline $\begin{array}{l}\text { Lack of institutionalized training program on PBC legal } \\
\text { framework }\end{array}$ & 14 & 88 \\
\hline High turnover of procurement professionals & 10 & 63 \\
\hline Fear of corruption & 7 & 44 \\
\hline Transparency problem & 4 & 25 \\
\hline
\end{tabular}

In addition, a second exclusive interview was conducted with the public officials who were not applying PBC in their procurement system. The interview questions were whether they know the concept and the benefits of PBC, as well as what the reasons were for not applying PBC in their procurement system even though the law allowed it. Fourteen informants from nine public organizations were interviewed. As indicated on table7, only five informants knew the concepts and the benefits of PBC for public procurement. The remaining nine informants knew nothing about the concepts and benefits of PBC. The reasons they mentioned for not applying PBC in their procurement system were that they were not given any training on the concepts and how to apply PBC in the public procurement system, as well as the lack of a clear legal framework in relation to PBC. 
Furthermore, the third group of interviews was conducted with seven procurement officials from organizations that had started to apply PBC in their procurement system. The interview was related to whether the application of PBC in their procurement system brought any benefit for them or their organization. The informants replied that they got many more benefits by applying PBC as compared to the traditional procurement system. The results of this and others are discussed in detail in the discussion section.

\section{TABLE 7}

Interview Results for Respondents from Organizations that are Not Applying PBC

\begin{tabular}{|c|c|}
\hline & No. of respondents \\
\hline Do not know the concepts and benefits of PBC & 9 \\
\hline Know the concepts and benefits of PBC & 5 \\
\hline Total & 14 \\
\hline
\end{tabular}

\section{DISCUSSION OF RESULTS}

Our analysis demonstrates the extent of application of PBC in the public procurement system of developing countries by considering the Ethiopian case of selected federal procuring entities. Of 13 procuring entities, only one of them has been using PBC, and it has done so only on the design-build-transfer types of contracts for road construction projects. However, the organization did not use PBC for its other procurements. This is more importantly due to fear of fraud and corruption, which is a very serious problem in the system. This is because PBC gives more emphasis to the qualitative aspects of the tendering process and is hence highly prone to bias in the selection process. Thus, PBC is at a pilot stage, having started only on a few road projects. On the other hand, six procuring entities including the Ethiopian Roads Authority included some elements of PBC together with detailed technical specifications. These organizations know the concept of PBC but are missing one or more elements of PBC. The remaining procuring entities did not include the concept of $\mathrm{PBC} /$ functional specifications in their contract or have not used PBC at all. This indicates that the practice of PBC is at its infancy stage even in the entity that partly used it. Thus, despite policy-level 
intentions, the concept of PBC has not yet cascaded to the ground level for implementation in many of the procuring entities.

Even though the PBC concept is clearly indicated in the procurement law, the public procuring entities have not been using it frequently in their procurement activities. This is partly due to the fact that the procurement directive of 2010 has limitations in terms of clearly defining how to use PBC and what the relations of public procurement officials should be with the contractors or suppliers. The directive lacks an appropriate level of reflection of the concept of PBC in it. This contributes to the procuring entities facing difficulties in understanding the concept and applying it in their procurement system. In addition, intensive and institutionalized training was not given to all parties involved in the public procurement process (both public and private).

The respondents were asked their views on the major impediments to applying PBC in the procurement system of public organizations. They listed a number of points as demonstrated in Table 6.

One of the reasons is lack of capacity by the procuring entities in the PBC system. Knowledge and skill gaps can lead to resistance to apply PBC (Kleemann \& Essig, 2013; Kleemann et al., 2012). When describing their worries, the respondents noted, 'The procurement system of the country has faced challenges with a shortage of professionals due to the low salary rate and lack of motivating incentives for maintaining skilled and qualified procurement professionals.' Trained and experienced public procurement officials have been leaving public organizations in search of a better salary.

One of the major functions of PPPAA is providing extensive procurement training and capacitating the public sector in public procurement (The Federal Government of Ethiopia, 2009). They have been giving procurement training to those who are involved in the procurement activities in public organizations. However, the PPPAA has not been offering any training for the public sector on PBC issues. As a result, the concept of PBC has not yet cascaded to the ground level in many of the public organizations. As demonstrated in Table 7, this leads to a situation in which the majority of the government officials and procurement professionals interviewed did not know the concept of PBC. A lack of clear understanding by the officials (from the regulatory authority and the top public officials) on the PBC 
concept also contributed to the low application of PBC in the public procurement system.

The other reason most of the respondents raised was that the public procurement directive of 2010 bypassed the concept of PBC. The PBC concept in proclamation number 649/2009 was not reflected and defined in the public procurement directive of 2010. Due to this gap, public procuring entities did not know even the concept of PBC, and they thought that PBC would be very difficult to apply in their procurement system. This is because; they usually work with the directive rather than the proclamation. Thus, they prefer to continue to use the traditional system of procurement instead of using PBC. This is confirmed by the fact that only one procuring entity uses the PBC system, and only in very few contracts. All the other procuring entities either did not know the concept of PBC and had not yet applied it in their procurement or knew the concept but did not have the capacity to apply it. Generally, the major problem in Ethiopia is lack of knowledge, practical experience, and clear legal framework to clearly define the concept. This is a matter that requires immediate intervention by the PPPAA.

Fear of corruption is one of the other reasons for the low practice of PBC in the public procurement system. In line with this, about $44 \%$ of the respondents expressed their fear that "applying PBC in the public procurement might increase the prevalence of corruption in the public organizations.' This is due to the fact that using least cost as the main tender evaluation criteria in the traditional contracting system minimizes having to make judgments on qualitative aspects of bids. Thus, they believe that PBC opens an opportunity to bias the selection result.

On the other hand, the respondents from public organizations that had started to practice the PBC system did not confirm this point. Rather, they noted that the PBC system minimizes some leaks or holes in the traditional procurement system in relation to the corruption that had been experienced previously.

Fear of transparency is noted by the respondents as one of the reasons for not practicing PBC in the public procurement system. This is due, in part, to the reality that the procurement directive does not clearly state how PBC can be used in the public procurement system. On the other hand, the other respondents who had started to use PBC in their procurement did not prove the suggestions above; rather, they 
strongly argued that PBC can enhance transparency by clearly indicating the responsibilities of each of the contracting parties.

Furthermore, the other interview was conducted with the officials of the public organization that had started to use PBC in their procurement about how the application of PBC has improved procurement in their organization. The respondents replied:

$[T]$ he very important thing for PBC is that the system needs to clearly define the problems that need to be solved instead of the processes for how to solve the problems. This enables the procuring entity to measure the end results of the contract. However, they need to design more quantifiable measurement indicators and have qualified personnel for the ongoing monitoring and to evaluate the end result. It also helps the procuring entity to establish an integrated decisionmaking system by reducing organizational fragmentation between the designer, the contractor and the client....

In line with the respondents' idea, the literature confirms that the main objectives of this type of contract are to bridge gaps that are found between different parties involved in the project execution process - for example, the client, designer, contractor and end user of the project (Ang, Groosman, \& Scholten, 2005). It also enhances creativity and innovation and enables the contractor to compete not only on price but also on quality. But it is only sustainable when the contract is supported by incentive modalities. Here, one organization can design and construct the project, and hence the number of parties involved in the implementation process is reduced. As a result, the conflicts that could arise between the client, the designer and the contractor can be minimized.

Using the PBC system also enhances a continuous dialogue among all involved parties in the construction process and helps to solve any problem in a timely manner (Becker, 2008). This improves the contract administration process as compared to the traditional contracting approach. In spite of all this, the contracts that practiced the PBC system are works contracts (design-build-transfer type of contracts in road construction projects), whereas PBC has not yet been fully practiced in other types of procurement, even in the same procuring entity. 
Generally, from the interview, the practitioner procurement officers have different views on PBC as compared to the nonpractitioners. A summary of their views is shown in Table 8 . These results demonstrate the need for policy-makers to give serious consideration to which should come first, 'enacting the law or capacitating the procurement professionals,' just like a 'chicken and egg' issue. It is similar to, for example, a case in which either someone purchases a vehicle using an alternative fuel without sufficient fuel stations to refuel it, or a fuel dealer opens fuel stations here and there without a sufficient number of alternative fuel vehicles to use them. The question is: Which should come first, from an economic standpoint? For our case, the choice is in the hands of the policy-makers, who must analyze the situation and make an appropriate decision.

Most importantly, procurement requires a high degree of skilled professionalism. It is believed that to achieve successful procurement, both the public and private sector managers should place more emphasis on people and on the knowledge and capabilities they need to be able to meet contemporary demands in the procurement sector. The procurement officials need to be familiar with the concepts of PBC, the relevant trends in technologies, markets, supply capabilities and skills (Brown \& Potoski, 2003; Pomazalová, 2011). This enhances knowledge about PBC and has a positive influence on the officials' attitude regarding the application of PBC in the procurement process. The views of the different respondents are summarized below in Table 8.

TABLE 8

Different Views of Respondents Applying PBC and Respondents Not Applying PBC

\begin{tabular}{|l|l|l|}
\hline Points & $\begin{array}{l}\text { Views of respondents } \\
\text { applying PBC }\end{array}$ & $\begin{array}{l}\text { Views of respondents } \\
\text { not applying PBC }\end{array}$ \\
\hline Corruption issues & $\begin{array}{l}\text { Enhances } \\
\text { accountability and } \\
\text { minimizes corruption }\end{array}$ & May increase corruption \\
\hline
\end{tabular}


TABLE 8 (Continued)

\begin{tabular}{|l|l|l|}
\hline Points & $\begin{array}{l}\text { Views of respondents } \\
\text { applying PBC }\end{array}$ & $\begin{array}{l}\text { Views of respondents } \\
\text { not applying PBC }\end{array}$ \\
\hline $\begin{array}{l}\text { Transparency } \\
\text { issues }\end{array}$ & $\begin{array}{l}\text { Can determine the } \\
\text { responsibility of each } \\
\text { party and enhance } \\
\text { transparency }\end{array}$ & $\begin{array}{l}\text { May reduce the } \\
\text { transparency of the } \\
\text { public procurement } \\
\text { process }\end{array}$ \\
\hline Procurement risk & $\begin{array}{l}\text { The procurement risks } \\
\text { transfer to the } \\
\text { contractor }\end{array}$ & $\begin{array}{l}\text { More of the } \\
\text { procurement risk is left } \\
\text { to the procuring entity } \\
\text { when using PBC }\end{array}$ \\
\hline
\end{tabular}

More importantly, the main objectives of the PBC approach are to lower the overall cost of acquisition and achieve the objectives of the procurement by focusing on performance results (Kleemann et al., 2012). However, price is still considered as the only and the most important evaluation criterion in Ethiopia in many of the public procurement projects. Public procurement in Ethiopia is still dominated by the principles of competition and fairness, but not qualities and performance results.

\section{The PPPAA's Future Plan}

The PPPAA has designed a plan to mitigate the challenges above and apply PBC in all the public procuring entities and hence to improve the efficiency and effectiveness of the public procurement system, reduce costs and enable both the procuring entities and the contractors to enjoy the benefits of applying PBC. The interviewees from the agency assured us that their organization has a plan to fully apply the PBC system in all the federal public organizations by:

- Providing an extensive and institutionalized training program including PBC and professionalizing the procurement sector in both public and private organizations.

- Revising the law in such a way that it clearly defines the concept of PBC, and designing different advocacy and sensitization programs about the benefits of applying PBC for all parties involved in the public procurement process (for both public and private organizations). 
- Establishing a monitoring system to check the applicability of PBC in the public procurement process.

Generally, PBC is not highly practiced in developing countries; hence, this paper provides practitioners in public procurement with new insights on the best practices of PBC, its challenges and its regulatory framework.

\section{Limitations of the Research}

Our research has limitations that could be addressed in future work. First, the findings of the research depend on a relatively qualitative analysis of contracts and interviews from some groups of public organizations. Thus, generalizability of this research finding would have limitations, as it covers a limited population; however, the objective is to achieve analytical generalizability. Payne \& Williams (2005) clarified that generalizability claims are less clear in qualitative research; however, they can be taken as benchmarks to conduct further research on the issue by studying a larger population and using both quantitative and qualitative analysis.

\section{CONCLUSION}

As presented in the analysis, PBC in the public procurement system of Ethiopia is a newly emerging concept, but it is, however, included in the public procurement proclamation. Perhaps one of the most important findings of this research work is that the public procuring entities are not practicing it more in their procurement system. Only one public organization has been applying PBC, and only in specific road construction projects. A few other procuring entities included some of the concepts of PBC or functional specifications together with detailed technical specifications.

The other important finding of this research work is that the procurement professionals who are using the PBC system and those who are not using the PBC system for their procurement have different views on the concepts and benefits of PBC. These result from either a lack of proper training on PBC issues or a lack of clear understanding of the law.

Training can enhance the understanding of the public officials on the concept of PBC, how and under which type of procurement PBC can be best applied and what benefits could be gained by using PBC. 
The training program should be organized for not only government officials but also private suppliers, consultants and contractors. In addition, revising the law in such a way that it clearly defines the concept of PBC to the extent that it can easily be understood by the user party should be the primary task to be performed by the regulatory authority.

\section{ACKNOWLEDGEMENTS}

This research was financed by the Netherlands organization for international cooperation in higher education (Nuffic), under grant no. $\mathrm{NICHE} / \mathrm{ETH} / 020$, and coordinated by Dr. Bertha Vallejo of Tilburg University, Center.

\section{REFERENCES}

African Development Bank (2008). Rules and Procedures for Procurement of Goods and Works. Abidjan, Ivory Coast: Author.

Ang, G., Groosman, M., \& Scholten, N. P. M. (2005). "Dutch Performance-based Approach to Building Regulations and Public Procurement." Building Research \& Information, 33(2): 107-119.

Anna, K. (2008). "Contracting in FM: Collaboration, Coordination and Control." Journal of Facilities Management, 6(3): 178-187.

Becker, R. (2008). "Fundamentals of Performance-based Building Design." Journal of Building Performance Simulation, 1: 356-371.

Berkowitz, D., Gupta, J. N. D., Simpson, J. T., \& McWilliams, J., B. (2005). "Defining and Implementing Performance-based Logistics in Government." Defense Acquisition Review Journal, 11(3): 255267.

Boykin, D. B. (2005). "What Performance-based Contracting Really Means for Procurement Goals." Government Procurement, 13(2): 6-9.

Brown, T. L., \& Potoski, M. (2003). "Managing Contract Performance: A Transaction Costs Approach." Journal of Policy Analysis and Management, 22(2): 275-297. 
Buchanan, N., \& Klingner, D. E. (2007). "Performance-based Contracting: Are we following the Mandete?" Journal of Public Procurement, 7(3): 302-332.

Claassen, M. J. T., van Weele, A. J., \& van Raaij, E. M. (2008). "Performance, Outcomes and Success Factors of Vendor Managed Inventory (VMI)." Supply Chain Management: An International Journal, 13(6): 406-414.

Doer, K., Lewis, I., \& Eaton, D. R. (2005). "Measurement Issues in Performance-based Logistics." Journal of Public Procurement, 5(2): 164-186.

Eldridge, C., \& Palmer, N. (2009). "Performance-based Payment: Some Reflectionson the Discourse, Evidence and Unanswered Questions." Health Policy and Planning, 24: 160-166.

Elo, S., \& Kyngas, H. (2008). "The Qualitative Content Analysis Process." Journal of Advanced Nursing, 62(1): 107-115.

Greiling, D. (2006). "Performance Measurement: A Remedy for Increasing the Efficiency of Public Services?" International Journal of Productivity and Performance Management, 55(6): 448-465.

Gruneberg, S., Hughes, W., \& Ancell, D. (2007). "Risk under Performance-based Contracting in the UK Construction Sector." Construction Management and Economics, 25: 691-699.

Guo, K., Minchin, E., \& Ferragut, T. (2005). "The Shift to Warranties and Performance Specifications: What of Method Specifications?" Construction Management and Economics, 23: 953-963.

Hannah, G., Ray, M., Wandersman, A., \& Chien, V. H. (2010). "Developing Performance-based Contracts between Agencies and Service Providers: Results from a Getting to Outcomes Support System with Social Service Agencies." Children and Youth Services Review, 32: 1430-1436.

Heaviside, B., \& Price, I. (2001). "Input versus Output-based Performance Measurement in the NHS: The Current Situation." Facilities, 19(10): 344-356.

Heinrich, C. J., \& Choi, Y. (2007). "Performance-based Contracting in Social Welfare Programs." The American Review of Public Administration, 37(4): 409-435. 
Hypko, P., Tilebein, M., \& Gleich, R. (2010). "Benefits and Uncertainties of Performance-based Contracting in Manufacturing Industries." Journal of Service Management, 21(4): 460-489.

Johnson, W. H. A., \& Medcof, J. W. (2007). "Motivating Proactive Subsidiary Innovation: Agent -based Theory and Socialization Models in Global R\&D." Journal of International Management, 13: 472-487.

Kestenbaum, M. I., \& Straight, R. L. (1995). "Procurement Performance Measuring Quality, Effectiveness, and Efficiency." Public Productivity \& Management Review, 19(2): 200-215.

Kettner, P. M., \& Martin, L. L. (1993). "Performance, Accountability, and Purchase of Service Contracting." Administration in Social Work, 17(1): 61-79.

Kim, S.-H., Cohen, M. A., \& Netessine, S. (2007). "Performance Contracting in After-sales Service Supply Chains." Management Science, 53(12): 1843-1858.

Kleemann, F. C., \& Essig, M. (2013). "A Providers' Perspective on Supplier Relationships in Performance-based Contracting." Journal of Purchasing \& Supply Management, 19(3): 185-198.

Kleemann, F. C., Glas, A., \& Essig, M. (2012). "Public Procurement through Performance-based Logistics: Conceptual Underpinnings and Empirical Insights." Journal of Public Procurement, 12(2): 151-188.

Kolar, K., Ahmad, F., Chan, L., \& Erickson, P. G. (2015). "Timeline Mapping in Qualitative Interviews: A Study of Resilience with Marginalized Groups." International Journal of Qualitative Methods, 14(3): 13-32.

Lam, E. W. M., Chan, A. P. C., \& Chan, D. W. M. (2007). "Benchmarking the Performance of Design-build Projects: Development of Project Success Index." Benchmarking: An International Journal, 14(5): 624-638.

Lawther, W. C., \& Martin, L. L. (2005). "Innovative Practices in Public Procurement Partnerships: The Case of the United States." Journal of Purchasing \& Supply Management, 11: 212-220.

Mannion, R., \& Davies, H. (2008). "Payment for Performance in Health Care." British Medical Journal (BMJ), 336(2): 305-308. 
Martin, L. L. (2007). "Performance-based Contracting for Human Services: A Proposed Model." Public Administration Quarterly, Add Vol \& issue \# Summar: 131-158.

Ng, I. C. L., Maull, R., \& Yip, N. (2009). "Outcome-based Contracts as a Driver for Systems Thinking and Service-dominant Logic in Service Science: Evidence from the Defence Industry." European Management Journal, 27: 377- 387.

Ng, I. C. L., \& Nudurupati, S. S. (2010). "Outcome-based Service Contracts in the Defense Industry: Mitigating the Challenges." Journal of Service Management, 21(5): 656-674.

Patil, S. S., \& Molenaar, K. R. (2011). "Risk Associated with Performance Specifications in Highway Infrustructure Procurement." Journal of Public Procurement, 11(4): 482-508.

Payne, G., \& Williams, M. (2005). “Generalization in Qualitative Research. Sociology" 39(2): 295-314.

Pomazalová, N. (2011). “Knowledge, Flawlessness and Failures in Processing of Public Procurement Documents at the State Administration." Acta Universitatis Agriculturae Et Silviculturae Mendelianae Brunensis, 59(7): 275-282.

Quinot, G., \& Arrowsmith, S. (Eds.). (2013). Public Procurement Regulation in Africa. New York, U.S.A.: Cambridge University Press.

Rosenthal, M. B., Fernandopulle, R., Ryu Song, H., \& Landon, B. (2004). “Paying for Quality: Providers' Incentives for Quality Improvement." Health Affairs, 23(2): 127-141.

Sabnis, G. M. (2005). "Performance-based Specifications for Concrete (P2P): Education Perspective, Progress and Future for Better Concrete." Paper Presented at the 30th Conference on our World in Concrete and Structures (OWICs), Howard University, Washington, DC.

Shen, Y. (2003). Selection Incentives in a Performance-based Contracting System. Health Services Research, 38(2), 535-551.

Straub, A., \& van Mossel, H. J. (2007). "Contractor Selection for Performance-based Maintenance Partnerships." International Journal of Strategic Property Management, 11(2): 65-76. 
Sumo, R., van der Valk, W., \& van Weele, A. J. (2012, April 1-4). "Performance-based Contracting as an Enabler of Innovation." Paper Presented at the 21st Annual IPSERA Conference, Naples, Italy.

"The Federal Government of Ethiopia, public Procurement and Property Administration Proclamation" (2009).

Tineo, L. (2007). "Procurement Issues in Performance-based Contracts: The World Bank Experience with Output-based Aid Subsidies." Journal of Public Procurement, 7(1): 62-83.

Twinn, S. (1997). "An Exploratory Study Examining the Influence of Translation on the Validity and Reliability of Qualitative Data in Nursing Research." Journal of Advanced Nursing, 26: 418-423.

Van Mossel, H.-J., \& Van der Valk, W. (2008). "Securing Customer Satisfaction through Component Service Specifications: Purchasing Maintenance Services for Social Rented Housing." Journal of Purchasing and Supply Management, 14(4): 241-252.

World Bank, \& Ethiopian Government (2010). "The Federal Democratic Republic of Ethiopia: Country Procurement Assessment Report (CPAR)." Paper Presented at the Discussion on Country Procurement Assessment Report Addis Ababa, Ethiopia.

World Bank (2011). Guidelines: Procurement of Goods, Works, and Non-consulting Services under IBRD Loans and IDA Credits \& Grants. Washington, DC: Author. 